\title{
Magnetic resonance velocity mapping: clinical application of a new technique
}

\author{
S R UNDERWOOD, D N FIRMIN, R H KLIPSTEIN, R S O REES, \\ D B LONGMORE \\ From the National Heart and Chest Hospitals, London
}

SUMMARY Magnetic resonance velocity mapping is a new technique which provides a display of velocity within the cardiovascular system at any point of the cardiac cycle. A short field echo sequence with even echo rephasing is used to obtain a signal from rapidly moving blood and a cine display is provided by rapid repetition of the sequence. The amplitude image shows the anatomy, with blood giving a high signal and areas of turbulent flow no signal. The phase image is a map of velocities at each point in the image plane. Thirteen cases are described in which the technique either provided a diagnosis or helped in functional assessment. Flow through atrial and ventricular septal defects was seen, although turbulent flow distal to the ventricular shunts led to some loss of quantitative information. In three patients with valve disease jets of abnormal flow were seen because of signal loss and it is suggested that the size of the area of turbulence may be used to quantify the severity of regurgitation. Velocities were measured in four coronary artery bypass grafts in two patients, and low velocity was seen in a graft with distal disease that supplied the infarcted territory. Velocity was reduced distal to an aortic coarctation and it was increased at the site of narrowing caused by thrombosis in a deep vein. The speed and direction of flow in the central vessels in a patient with complex congenital heart disease helped to establish the anatomy.

The technique provides useful information in a wide range of disorders of the cardiovascular system, and in some cases may avoid the need for invasive investigation.

Magnetic resonance imaging of the heart provides excellent anatomical detail because conventional sequences show a high contrast between flowing blood and other structures. ${ }^{1-3} \mathrm{~A}$ wide variety of abnormalities can be studied including congenital disease, ${ }^{4-6}$ myocardial disease, ${ }^{7-9}$ and disease of the pericardium ${ }^{1011}$ and great vessels. ${ }^{12-14}$ Cardiac function may also be studied by measuring chamber volumes at end diastole and end systole, and left and right ventricular stroke volumes, ejection fractions, and output can be calculated from these volumes. ${ }^{15}$ These measurements are valuable in the assessment of valvar regurgitation ${ }^{16}$ and atrial shunting, ${ }^{17}$ but velocity mapping provides additional information which is useful in a wider range of conditions.

Requests for reprints to Dr S R Underwood, Magnetic Resonance Unit, The National Heart and Chest Hospitals, 30 Britten Street, London SW3 6NN.

Accepted for publication 3 February 1987
Moran et al first proposed encoding velocity in the phase of the magnetic resonance signal ${ }^{18}$ and several groups subsequently acted on this suggestion. ${ }^{19-22}$ The velocity map arises from a display of phase at each point in the image instead of the conventional display of amplitude, but a sequence that maintains the signal from flowing blood must be used. We have previously described a short field echo sequence with even echo rephasing which is suitable ${ }^{23}$ and by comparing aortic flow measured from aortic velocity with that measured by left ventricular stroke volume we have shown the new method to be accurate in vivo. ${ }^{24}$ Refinements of the technique include cine acquisition to provide information at all parts of the cardiac cycle and superimposition of colour coded velocities upon the conventional anatomical image to give an easily interpretable display of anatomy and flow. ${ }^{25}$ Acceleration may also be measured, and although this has important potential applications its clinical value is not yet established. 
This paper is the first report of the clinical application of magnetic resonance velocity mapping. Thirteen patients are described in whom the technique was valuable either in establishing the initial diagnosis or in assessing the functional importance of the diagnosis.

\section{Patients and methods}

We used a Picker International Vista MR2055 magnetic resonance scanner operating at $0.5 \mathrm{~T}$. For the anatomical images, electrocardiographic gating was used with two repetitions of 128 spin echo sequences (echo time $24 \mathrm{~ms}$ ). The slice thickness was $10 \mathrm{~mm}$ and the images were displayed on a $256 \times 256$ matrix with a pixel size of $1.17 \times 1.17 \mathrm{~mm}$. The acquisition time was between three and four minutes depending upon heart rate, but two images were usually acquired synchronously (end diastole at one level with end systole at another).

Velocity mapping was performed using a field echo sequence with even echo rephasing (echo time $21 \mathrm{~ms}$ ) and with gradient modifications to encode velocity in any of three orthogonal directions, either in the plane of the image or perpendicular to it. The slice thickness and resolution were the same as for the spin echo sequence. The sequence was repeated up to a maximum of 12 times per cardiac cycle with a reduced excitation pulse angle ${ }^{26}$ in order to acquire information throughout the cycle. Magnitude reconstruction provided an anatomical image with high signal from blood (in contrast with the low signal obtained with conventional spin echo sequences), and phase reconstruction provided a map of velocity in the chosen direction after the phase map without velocity encoding had been subtracted to compensate for phase changes introduced by field inhomogeneity. To eliminate random phase values from background noise the velocity image was masked to show zero velocity in pixels with $<10 \%$ of maximum magnitude.

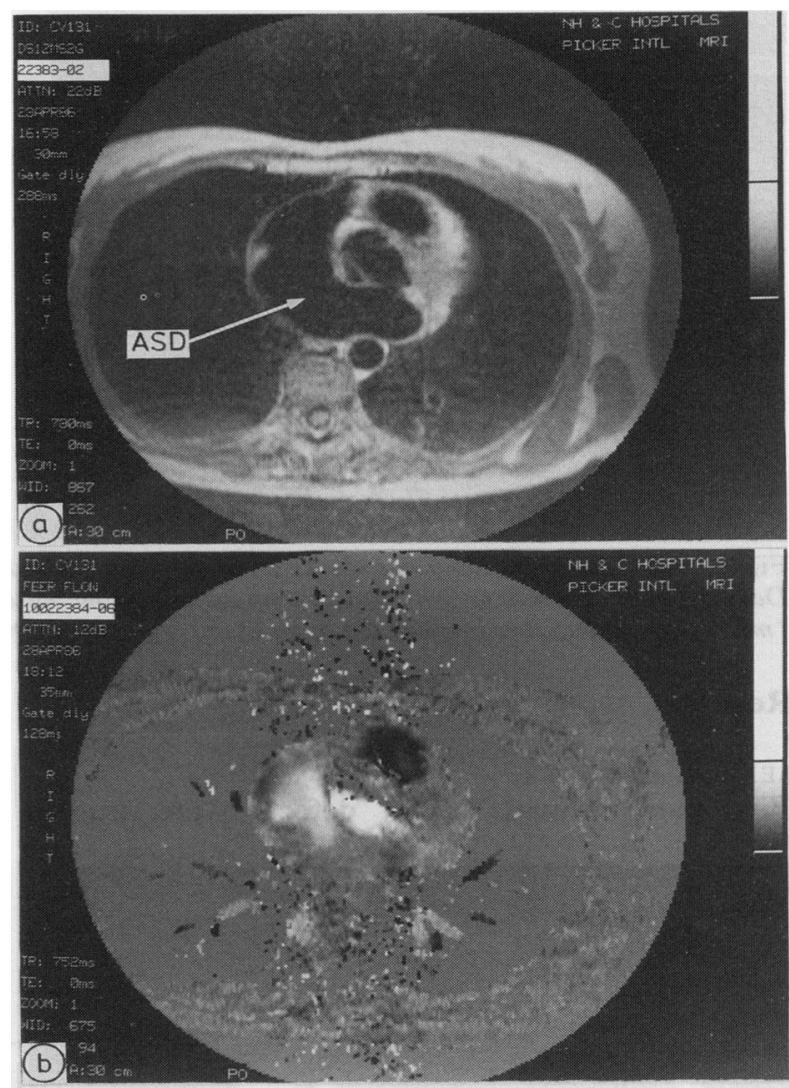

Fig 1 (a) Transverse magnetic resonance image at mid-atrial level showing an ostium secundum atrial septal defect ( $A S D)$. The right atrium is dilated and right and left ventricular stroke volumes gave a pulmonary to systemic flow ratio of $2 \cdot 1$. (b) Mid-systolic velocity map of the same section coded from posterior to anterior. Zero velocity is shown in mid-grey, velocities from posterior to anterior in shades of light grey, and those from anterior to posterior in shades of dark grey. There is flow from left atrium to right atrium through the defect (light grey) as well as flow in the aortic root (white), pulmonary artery (black), and pulmonary veins.

Table 1 Magnetic resonance findings in five patients with intracardiac septal defects

\begin{tabular}{|c|c|c|c|c|}
\hline \multicolumn{2}{|c|}{ Patient } & \multirow{2}{*}{$\begin{array}{l}\text { Age } \\
47 \\
17\end{array}$} & \multirow{2}{*}{$\begin{array}{l}\text { Abnormality } \\
\text { Secundum ASD } \\
\text { Primum ASD with Dacron patch. Mild aortic coarctation }\end{array}$} & \multirow{2}{*}{$\begin{array}{l}\text { Findings } \\
\text { Left to right flow through defect. No turbulent flow } \\
\text { No flow through atrial septum. No turbulence within } \\
\text { atria }\end{array}$} \\
\hline $\begin{array}{l}1 \\
2\end{array}$ & $\mathbf{F}$ & & & \\
\hline 3 & $\mathbf{F}$ & 17 & $\begin{array}{l}\text { Pulmonary atresia with homograft conduit. Subaortic VSD } \\
\text { with Dacron patch but detached sutures }\end{array}$ & $\begin{array}{l}\text { Dacron patch invisible. Left to right flow through } \\
\text { VSD with downstream turbulence }\end{array}$ \\
\hline 4 & $\mathbf{M}$ & 46 & Separate VSDs from $L V$ to $R V$ and $L V$ to $R A$ & $\begin{array}{l}\text { Separate jets with downstream turbulence, the larger } \\
\text { jet from LV to RA }\end{array}$ \\
\hline 5 & $\mathbf{M}$ & 15 & $\begin{array}{l}\text { Pulmonary atresia with pericardial conduit to hypoplastic } \\
\text { PAs and systemic collaterals. Subaortic VSD }\end{array}$ & RV to LV flow through VSD. No turbulence \\
\hline
\end{tabular}

ASD, atrial septal defect; VSD, ventricular septal defect; LV, left ventricle; RV, right ventricle; RA, right atrium; PA, pulmonary artery. 

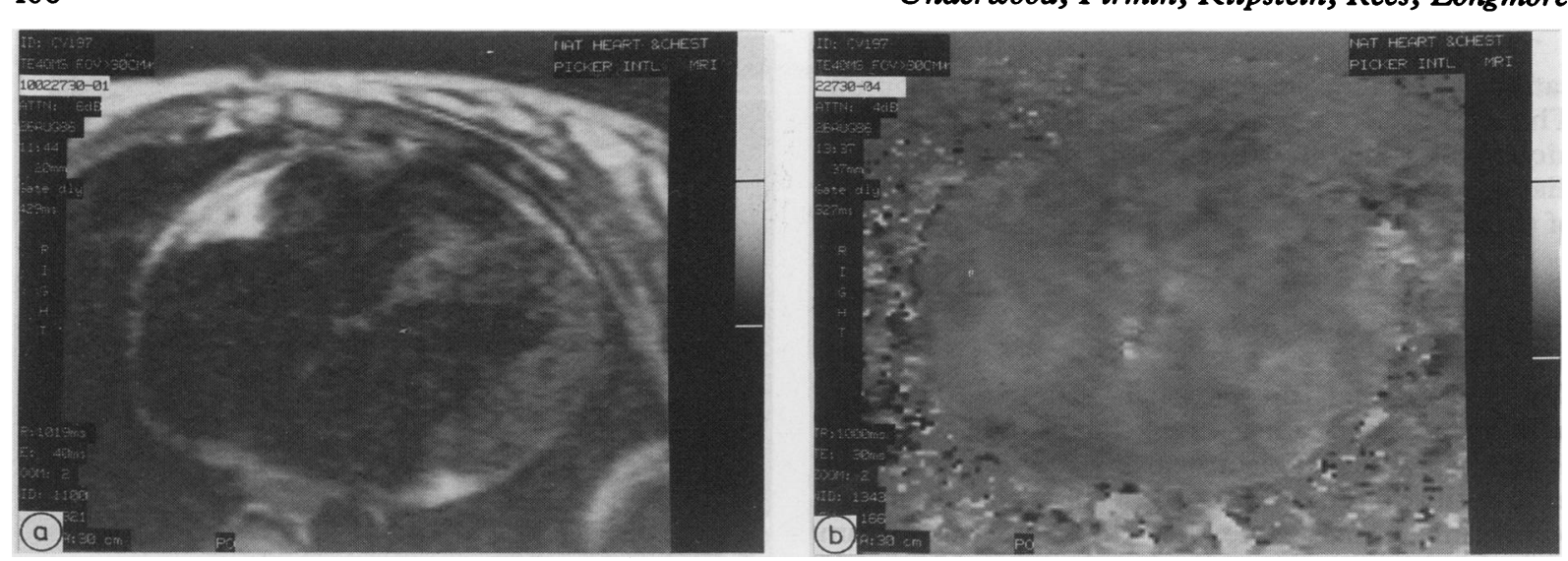

Fig 2 (a) Transverse magnetic resonance image showing an ostium primum atrial septal defect that had been closed by a Dacron patch (not seen). (b) Velocity map encoded from posterior to anterior showing very low velocities in all chambers (mid-grey) and no flow between the atria in the region of the patch.

\section{Results}

\section{SEPTAL DEFECTS}

Five patients with septal defects were studied
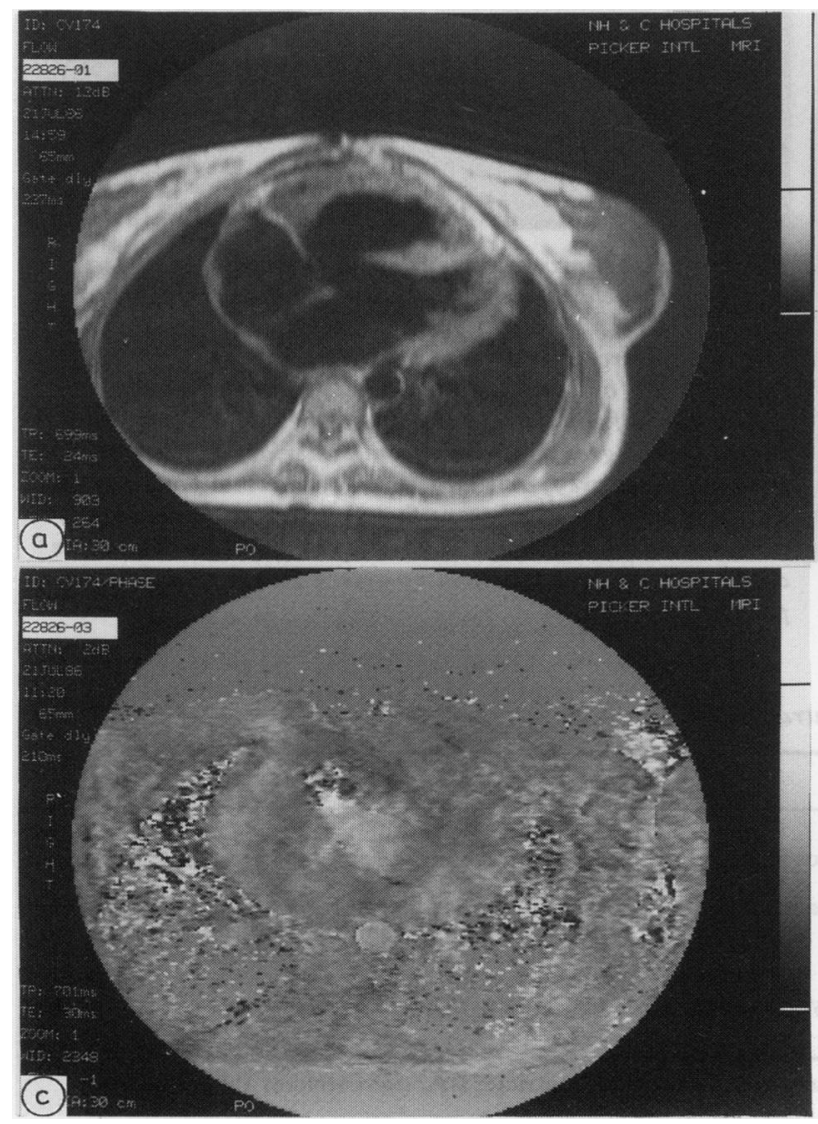

(table 1). Patient 1 was initially thought to have either an atrial septal defect or pulmonary stenosis. Echocardiography was not able to demonstrate the atrial septum adequately but radionuclide angio-

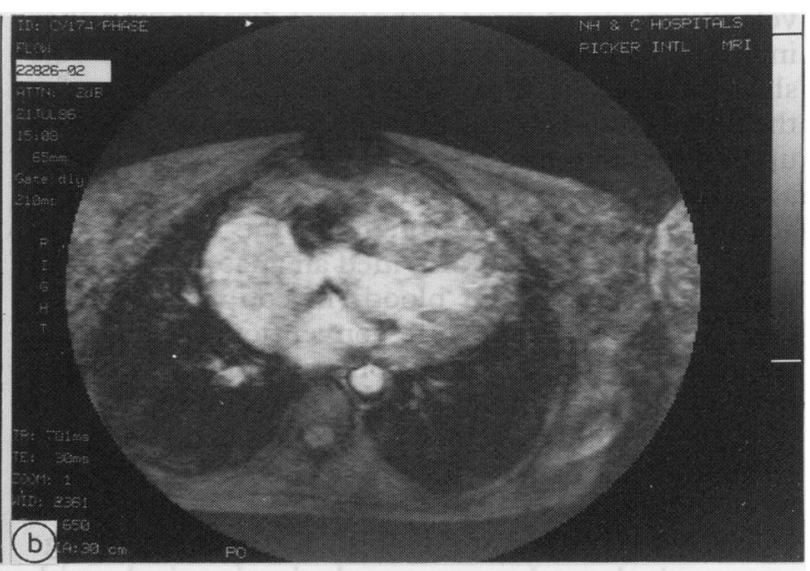

Fig 3 (a) Transverse spin echo image showing a ventricular septal defect that had been closed by a Dacron patch. (b) Field echo image showing high signal (white) from the blood but loss of signal (black) in the right ventricle caused by turbulent flow through the defect. (c) Velocity map encoded from posterior to anterior showing flow through the defect (white). 

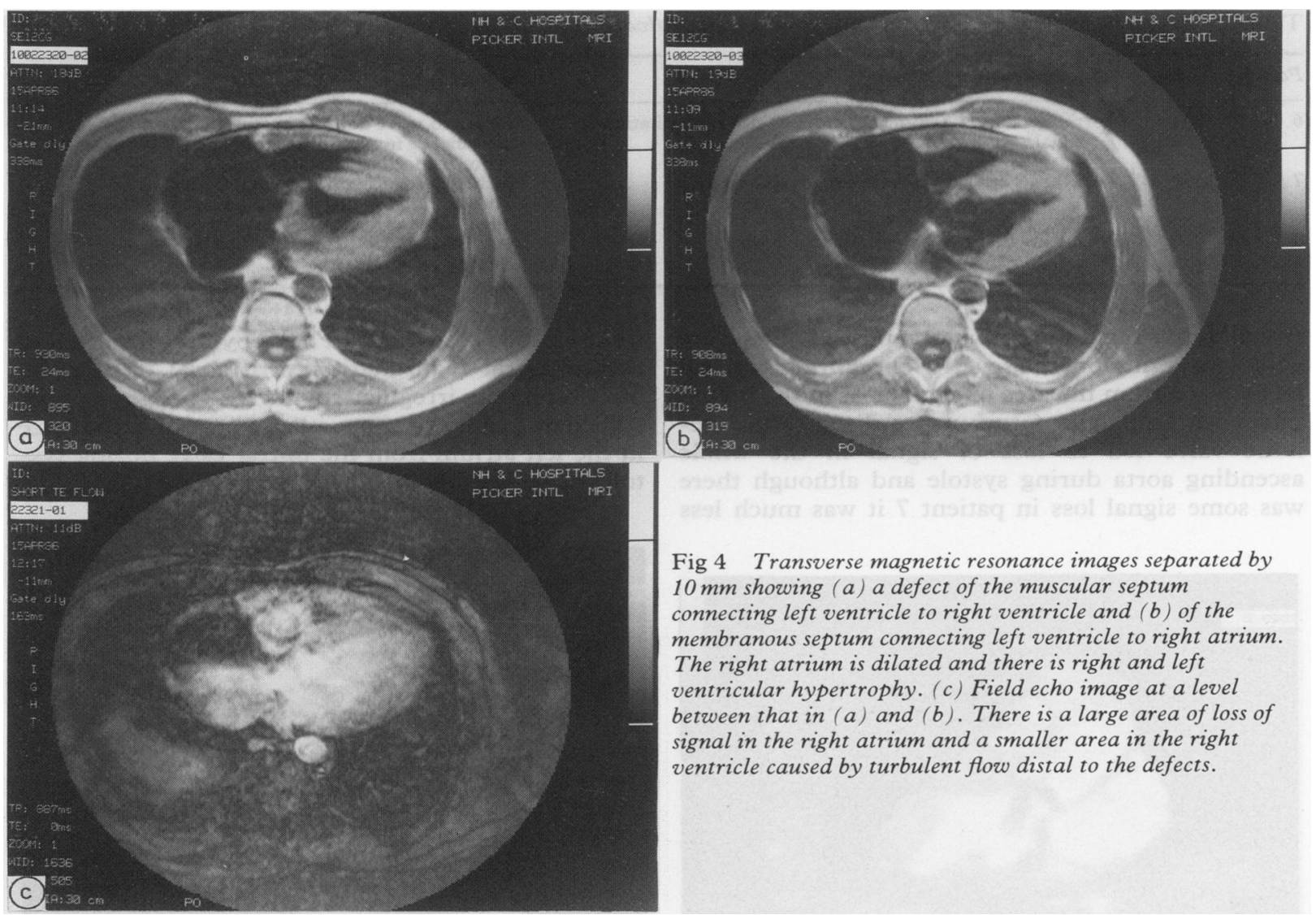

Fig 4 Transverse magnetic resonance images separated by

$10 \mathrm{~mm}$ showing (a) a defect of the muscular septum connecting left ventricle to right ventricle and $(b)$ of the membranous septum connecting left ventricle to right atrium. The right atrium is dilated and there is right and left ventricular hypertrophy. (c) Field echo image at a level between that in $(a)$ and $(b)$. There is a large area of loss of signal in the right atrium and a smaller area in the right ventricle caused by turbulent flow distal to the defects.

cardiography showed a left to right shunt with a pulmonary to systemic flow ratio of 2.3 and a left ventricular ejection fraction of $0 \cdot 61$. Magnetic resonance imaging showed an ostium secundum atrial septal defect and a dilated right heart (fig 1a) and from stroke volume measurements the pulmonary to systemic flow ratio was calculated to be $2 \cdot 1$. Figure $1 \mathrm{~b}$ shows a mid-systolic phase map with velocity encoded from posterior to anterior. Flow velocities are seen on both sides of the defect passing from left atrium to right atrium, and the maximum velocity was $427 \mathrm{~mm} / \mathrm{s}$ in early systole.

Patient 2 also had an atrial septum defect; this had been closed with a Dacron patch. Figure 2 shows the defect in transverse section and because Dacron gives no magnetic resonance signal the patch is invisible. The velocity map, however, shows no flow between the atria, so the patch can be assumed to be intact.

In contrast, patient 3 had a Dacron patch to a ventricular septal defect but the patch had become partially detached. There is an area of loss of signal in the amplitude image of the field echo sequence caused by turbulent flow (fig 3 ). This indicates the presence of a left to right shunt through the defect and although quantitative velocity information is lost in this region the size of the area of turbulence is considerable.

Patient 5 had separate defects between left and right ventricles and between left ventricle and right atrium (fig 4). The magnitude field echo image during systole showed a large area of loss of signal in the right atrium and a smaller area in the right ventricle, implying that a greater part of the left to right shunting was from left ventricle to right atrium. This was confirmed by cardiac catheterisation.

\section{VALVAR HEART DISEASE}

Three patients with valvar disease were studied (table 2). All three had areas of signal loss in the field echo amplitude images which led to loss of accurate velocity measurements, but because these areas corresponded to jets of abnormal flow useful information was still obtained. Figure 5 shows a patient with 
Table 2 Magnetic resonance findings in three patients with valve disease

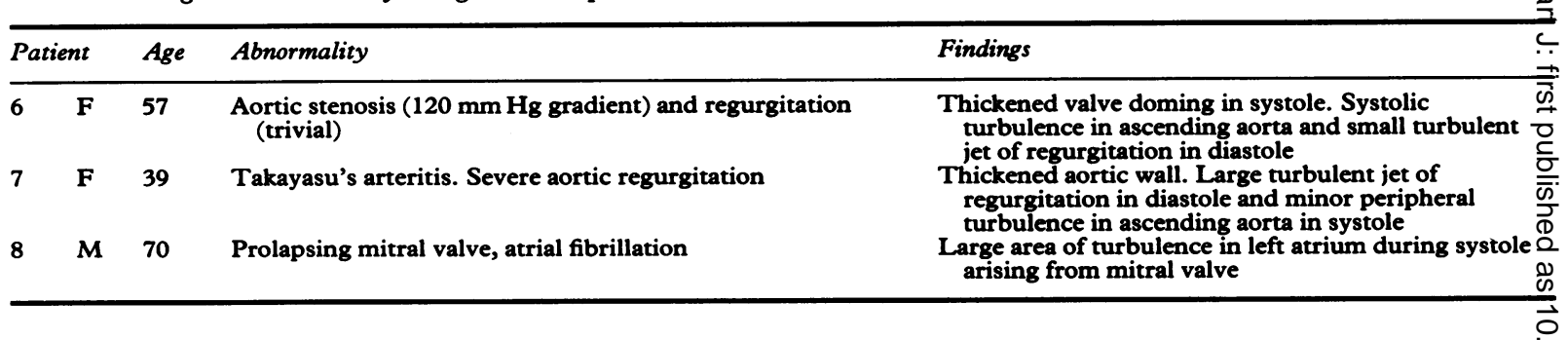

trivial aortic regurgitation and another with severe aortic regurgitation; the severity of regurgitation can be assessed from the area of signal loss in the regurgitant jet. In patient 6 turbulence distal to the stenotic valve led to loss of signal in the whole ascending aorta during systole and although there was some signal loss in patient 7 it was much less
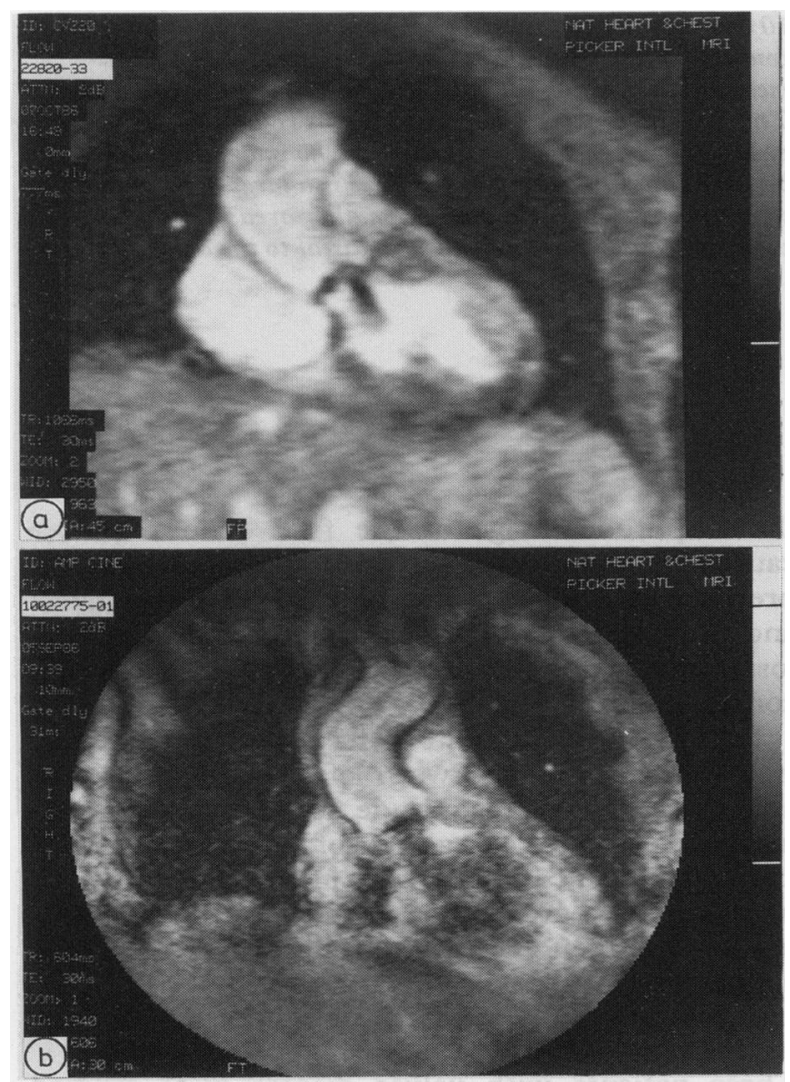

Fig 5 (a) Diastolic coronal field echo image through the aortic valve in patient 6 with severe aortic stenosis and trivial regurgitation. The thickened valve appears as a black line and the regurgitation is seen as a small turbulent jet leading to loss of signal. (b) Equivalent image in patient 7 with severe regurgitation. The turbulent regurgitant jet is much larger. pronounced. Patient 8 had a floppy mitral valve and severe mitral regurgitation with atrial fibrillation but despite the irregular rhythm the images were of sufficient quality to show a large area of turbulence in the left atrium from the mitral valve during systole.

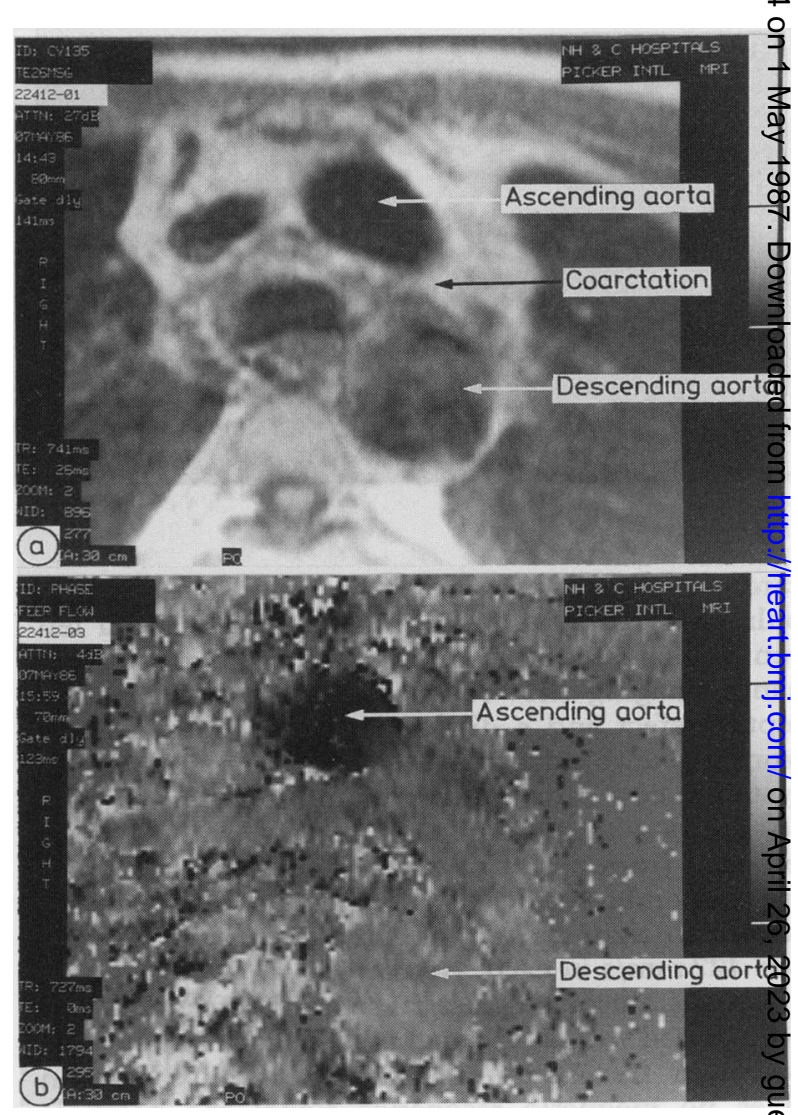

Fig 6 (a) Transverse image through the aortic arch in mid-systole showing a coarctation. Signal from blood distal te the narrowing suggests slow flow. The right internal mammary artery is dilated. (b) Velocity mapping at a moreD caudal level showed peak velocities to be $406 \mathrm{~mm} / \mathrm{s}$ in the ascending aorta (black) and $103 \mathrm{~mm} / \mathrm{s}$ in the descending aorta (light grey). 

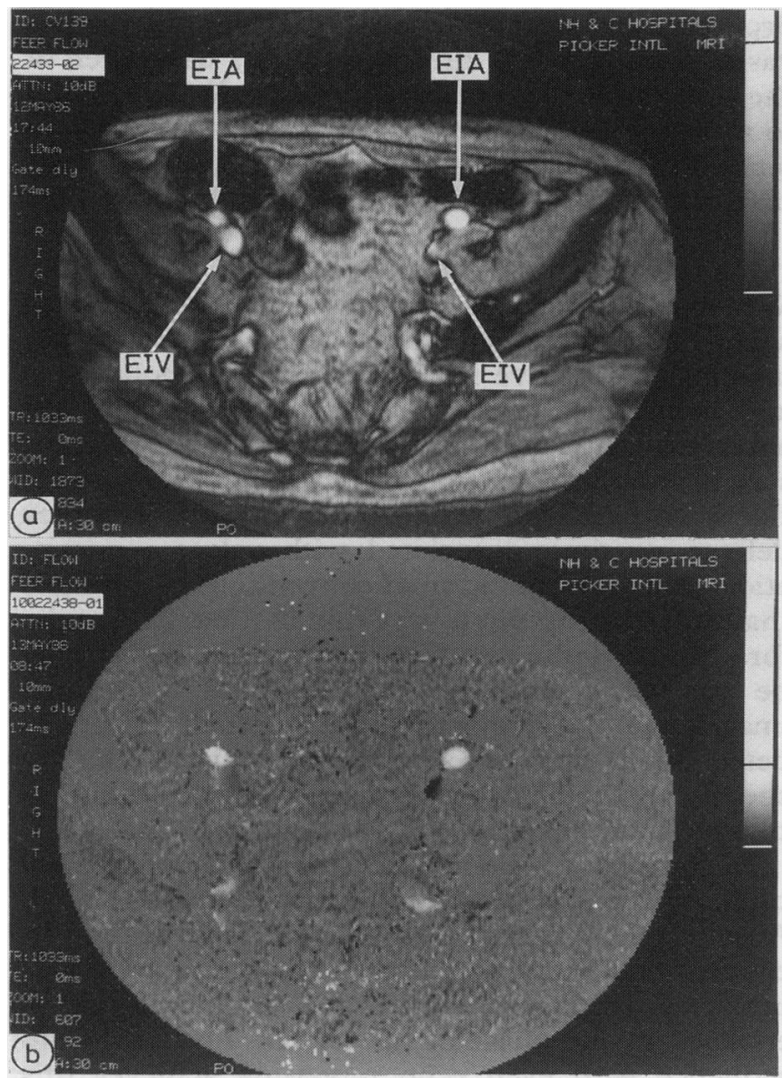

Fig 7 (a) Transverse image through the mid-pelvis using the field echo sequence. There is high signal from the external iliac arteries (EIA) and veins (EIV), and the left external iliac vein is partially occluded. (b) Velocity map perpendicular to the plane. High velocities in the iliac arteries are shown in white (peak velocity left $260 \mathrm{~mm} / \mathrm{s}$, right $252 \mathrm{~mm} / \mathrm{s}$ ), and low velocities in the right external iliac vein in dark grey (peak velocity $58 \mathrm{~mm} / \mathrm{s}$ ). Rapid flow in the left external iliac vein at the level of the partial obstruction is seen in black (peak velocity $213 \mathrm{~mm} / \mathrm{s}$ ). Velocities in the internal iliac arteries are also seen posteriorly.

\section{AORTIC COARCTATION}

A 50 year old man with hypertension and a BjörkShiley mitral valve was thought clinically to have aortic coarctation but aortography failed to produce diagnostic images. Magnetic resonance imaging showed a tight constriction of the aortic arch at the level of the left carotid orifice and the right internal mammary artery was dilated (fig 6). The signal from blood distal to the constriction suggested slow moving blood, and velocity mapping showed a peak velocity of $406 \mathrm{~mm} / \mathrm{s}$ in the ascending aorta (normal range 370 to $690 \mathrm{~mm} / \mathrm{s}^{24}$ but only $103 \mathrm{~mm} / \mathrm{s}$ in the descending aorta (normal range 283 to $711 \mathrm{~mm} / \mathrm{s}^{24}$

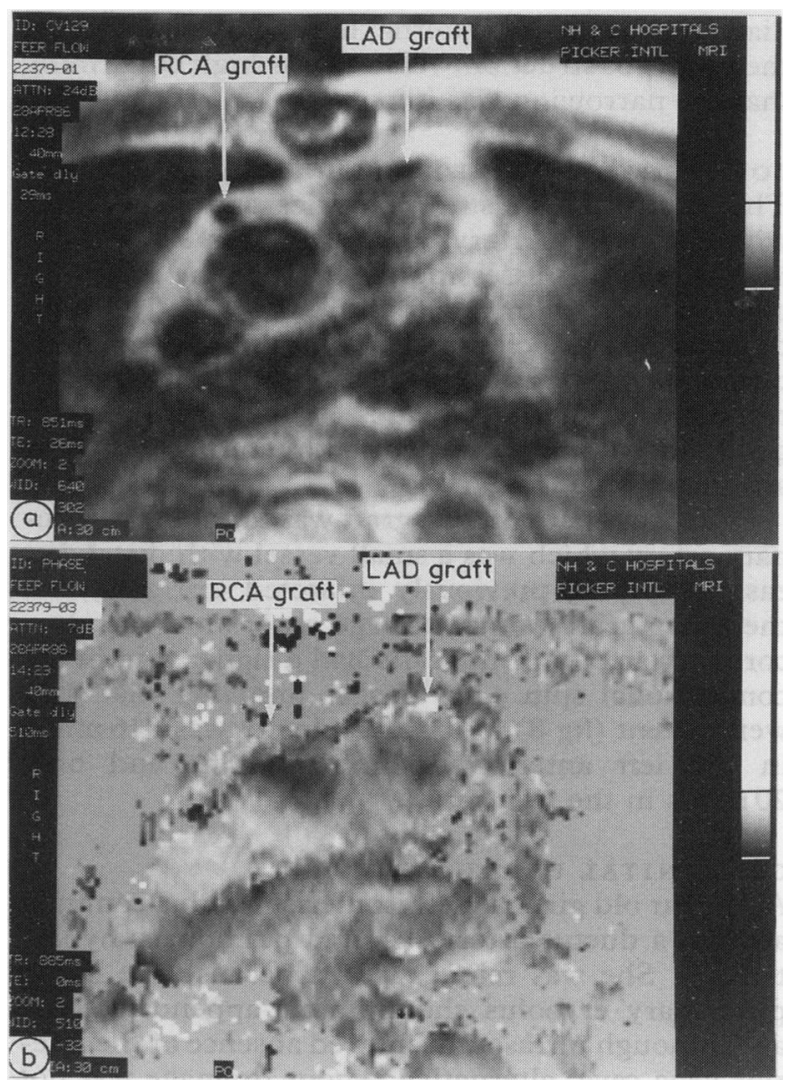

Fig 8 (a) Transverse image through the aortic root showing coronary artery bypass grafts to the right (RCA) and left anterior descending ( $L A D)$ coronary arteries (arrowed). The anterior descending graft passes obliquely through the plane of the image. The absence of signal in the grafts suggests that they are patent. There is an artefact in the region of the sternum caused by a wire suture.

(b) Mid-diastolic velocity map encoded through the plane of the image, with caudal velocities shown in white. Mean velocity in the left anterior descending graft is high

$(316 \mathrm{~mm} / \mathrm{s})$, but in the right coronary graft it is low $(20 \mathrm{~mm} / \mathrm{s})$.

This low velocity confirmed the functional importance of the stenosis.

\section{VENOUS THROMBOSIS}

A 52 year old man with thromboangiitis obliterans (Buerger's disease) and a right below knee amputation developed a left sided deep venous thrombosis which was confirmed by venography. The signs resolved completely, and magnetic resonance imaging after recovery showed an irregular but patent left external iliac vein (fig 7). Velocity mapping showed high systolic velocities in the external and internal iliac arteries, and low velocities in the right external 
iliac vein. In the left external iliac vein at the level of the partial obstruction, velocity was high confirming that the narrowing was important.

\section{CORONARY ARTERY BYPASS GRAFTS}

The ability to measure velocities and hence flow within coronary artery bypass grafts is expected to be important in assessing function of the grafts. In one patient with grafts to the left anterior descending and circumflex territories, peak middiastolic velocities were $118 \mathrm{~mm} / \mathrm{s}$ and $141 \mathrm{~mm} / \mathrm{s}$ respectively. Both velocities are compatible with good flow ${ }^{27}$ and accorded with findings at $x$ ray arteriography.

In another patient, one graft was to the right coronary artery which was a small vessel with distal disease supplying previously infarcted territory, and the other graft was to a large anterior descending coronary artery. Both grafts had a signal void in the conventional spin echo images implying that they were patent (fig 8), but peak velocity was $316 \mathrm{~mm} / \mathrm{s}$ in the left anterior descending graft and only $20 \mathrm{~mm} / \mathrm{s}$ in the right graft.

\section{CONGENITAL HEART DISEASE}

A 15 year old girl had left isomerism with a common atrium, a ductus arteriosus, and pulmonary hypertension. She was reinvestigated because she had a pulmonary embolus shortly after appendicectomy and although ultrasound showed absence of the inferior vena cava, alternative venous drainage was not identified. Magnetic resonance imaging confirmed the cardiac anatomy and showed that the hepatic veins drained directly into the right atrium. A large left sided azygos vein was identified draining to a left sided superior vena cava and thence to a dilated coronary sinus. In the conventional images it was difficult to distinguish between the azygos vein and the descending aorta, but velocity mapping showed rapid caudal flow in the aorta (peak velocity $640 \mathrm{~mm} / \mathrm{s}$ ) and slower cranial flow in the vein (peak velocity $150 \mathrm{~mm} / \mathrm{s}$ ).

\section{Discussion}

Magnetic resonance was first used to measure blood flow in 1959 by Singer in the mouse tail. ${ }^{28}$ Since then many different methods have been developed, but this technique is the first to have proved suitable for routine use. Methods based on time of flight between two planes produce semiquantitative measurements in blood vessels ${ }^{29}$ but they are not applicable in the heart, and those based upon flow of blood into a magnetically saturated plane $\mathrm{e}^{30}$ are also difficult to quantify. Methods that use phase changes induced by motion along a field gradient have proved to be the most versatile within the cardiovascular system, but previous reports have been of the qualitative detection of flow only. ${ }^{31}$ The ability to measure velocities within the cardiovascular system is likely to be useful in various situations and the cases we present have been chosen to illustrate this.

INTRACARDIAC APPLICATIONS

We have described the findings in five patients with septal defects. Conventional magnetic resonance imaging is sensitive in the detection of both atrial and ventricular defects ${ }^{32} 33$ and although the left and right ventricular stroke volumes provide a measure of interatrial shunting, they are not helpful for the quantification of ventricular shunts, complex defects, or those associated with valvar regurgitation. Another limitation of conventional imaging is that the atrial septum is very thin in the region of the foramen secundum so that an apparent defect may be misleading and specificity is poor ${ }^{34}$ Oblique images and cine acquisition are helpful ${ }^{35} 36$ but the detection of flow across a defect must be highly specific and velocity mapping is a useful addition to conventional imaging.

In some cases velocity measurements are complicated by the loss of the magnetic resonance signal. Absent signal from moving blood is beneficial in conventional imaging, but in velocity mapping it is important to avoid signal loss since velocity is encoded in the phase of the signal. The field echo sequence with even echo rephasing achieves this despite rapid movement of blood, but signal can be lost in the presence of turbulence and the ability to measure velocity is then lost. Despite this, the size of the area of signal loss may be helpful in assessing shunts and regurgitation, ${ }^{37}$ although other factors such as the size and nature of the orifice and the pressure difference across it will also affect the degree of turbulence.

The loss of signal has several causes and there is not necessarily an exact correspondence between signal loss and turbulence. The main reason for this is the presence of different values of higher order terms of motion (such as acceleration) within a single pixel. This always occurs in turbulent flow and although it does not usually occur in the normal heart, it sometimes leads to signal loss during early diastolic filling through the mitral valve and around the periphery of the aortic root during systole.

The detection of turbulence is used in Doppler echocardiography where the severity of valvar regurgitation is assessed from the depth of penetration of the regurgitant jet into the upstream chamber. ${ }^{38}$ Doppler ultrasound can also produce velocity maps ${ }^{39}$ and it has some advantages over magnetic resonance: real time imaging is possible 
and turbulent flow does not lead to loss of information (although it may complicate interpretation). Important disadvantages are that it is less accurate, ${ }^{40}$ high and low velocities are difficult to measure, ${ }^{41}$ and access to the heart is limited, particularly for large posterior vessels.

\section{VASCULAR APPLICATIONS}

The cases of coarctation and venous thrombosis illustrate the potential applications of velocity mapping in the assessment of vascular disease. A velocity profile through a stenosis provides a measure of its functional importance and the pressure gradient across the stenosis can be estimated. 4243 Conventional magnetic resonance imaging has already been used to assess peripheral vascular disease ${ }^{445}$ but velocity and acceleration mapping will provide important additional information since it is the effect of disease upon perfusion that determines prognosis. Coronary artery bypass grafts have also been studied before but without velocity measurements, ${ }^{46}$ and a comparison between velocity mapping and other measurements of graft function is now required. A combination of magnetic resonance angiography ${ }^{47}$ with velocity and acceleration mapping offers the prospect of a completely non-invasive assessment of vascular disease.

We have validated velocity and flow measurements in phantom experiments, in the femoral artery, and in the ascending aorta ${ }^{24}$ but velocity is only measured in a single direction in each velocity map and it is important to know the angle between the vessel and the plane in which it is imaged, or alternatively to make measurements in three orthogonal directions. For small vessels there are additional sources of inaccuracy such as the partial volume effect, and small vessels are best studied perpendicular to the plane of the image. Resolution may not yet be adequate for accurate flow calculations in coronary bypass grafts or coronary arteries but these preliminary results are encouraging.

\section{Conclusion}

Magnetic resonance velocity mapping is a new technique that provides a display of velocity within the cardiac chambers and major vessels at any point of the cardiac cycle. It is expected to be applicable in a wide variety of disorders of the cardiovascular system, and it may avoid invasive investigation in some cases. It is likely to be valuable in the assessment of intracardiac shunting, valve regurgitation and stenosis, and in the measurement of flow in congenital heart disease. Most exciting is its potential for the detection and assessment of vascular disease, including disease of the coronary arteries.
We thank the following for financial support: the Board of Governors of the National Heart and Chest Hospitals, the Coronary Artery Disease Research Association (CORDA), the League of Friends of The Brompton Hospital, the Viscount Royston Trust, the Halley Stewart Trust, the Charles Wolfson Charitable Foundation, and GEC/Picker International. We thank Sister Elizabeth Burman and Mr Karl Lotey for their help.

\section{References}

1 Steiner RE, Bydder GM, Selwyn A, et al. Nuclear magnetic resonance imaging of the heart. Current status and future prospects. Br Heart J 1983; 50:202-8.

2 Lieberman JM, Alfidi RJ, Nelson AD, et al. Gated magnetic resonance imaging of the normal and diseased heart. Radiology 1984;152:465-70.

3 Higgins CB, Byrd BF, McNamara MT, et al. Magnetic resonance imaging of the heart: a review of the experience in 172 subjects. Radiology 1985;155: 671-9.

4 Fletcher BD, Jacobstein MD, Nelson AD, Riemenschneider TA, Alfidi RJ. Gated magnetic resonance imaging of congenital cardiac malformations. Radiology 1984;150:137-40.

5 Fisher MR, Hricak H, Higgins CB. Magnetic resonance imaging of developmental venous anomalies. Am J Roentgenol 1985;145:705-9.

6 Didier D, Higgins CB, Fisher MR, Osaki L, Silverman $\mathrm{NH}$, Cheitlin MD. Congenital heart disease: gated MR imaging in 72 patients. Radiology 1986;158: 227-35.

7 McNamara MT, Higgins CB, Schechtmann N, et al. Detection and characterisation of acute myocardial infarction in man with use of gated magnetic resonance. Circulation 1985;71:717-24.

8 Higgins CB, Lanzer $\mathrm{P}$, Stark $\mathrm{O}$, et al. Imaging by nuclear magnetic resonance in patients with chronic ischaemic heart disease. Circulation 1984;69:523-31.

9 Underwood SR, Rees RSO, Savage PE, et al. Assessment of regional left ventricular function by magnetic resonance. $B r$ Heart $J$ 1986;56:334-40.

10 Stark DD, Higgins CB, Lanzer P, et al. Magnetic resonance imaging of the pericardium: normal and pathologic findings. Radiology 1984;150:469-74.

11 Soulen RL, Stark DD, Higgins CB. Magnetic resonance imaging of constrictive pericardial disease. $\mathrm{Am}$ $J$ Cardiol 1985;55:480-4.

12 Amparo EG, Higgins CB, Shafton EP. Demonstration of coarctation of the aorta by magnetic resonance imaging. Am J Roentgenol 1984;143:1192-4.

13 Glazer HS, Gutierrez FR, Levitt RG, Lee JKT, Murphy WA. The thoracic aorta studied by MR imaging. Radiology 1985;157:149-55.

14 McMurdo KK, de Greer G, Webb WR, Gamsu G. Normal and occluded mediastinal vessels: MR imaging. Radiology 1986;159:33-8.

15 Longmore DB, Klipstein RH, Underwood SR, et al. 
Dimensional accuracy of magnetic resonance in studies of the heart. Lancet 1985;i:1360-2.

16 Underwood SR, Klipstein RH, Firmin DN, et al. Magnetic resonance assessment of aortic and mitral regurgitation. Br Heart J 1986;56:455-62.

17 Underwood SR, Klipstein RH, Firmin DN, et al. Magnetic resonance assessment of the accuracy of radionuclide methods for the quantification of valvular regurgitation and atrial shunting. In: Hoefer $R$, Bergman $\mathrm{H}$, eds. Radioactive isotopes in medicine and research. Vienna: Verlag $\mathrm{H}$ Egerman, 1986;17:299-305.

18 Moran PR. A flow velocity zeugmatographic interlace for NMR imaging in humans. Magnetic Resonance Imaging 1982;1:197-203.

19 Bryant DJ, Payne JA, Firmin DN, Longmore DB. Measurement of flow with NMR imaging using a gradient pulse and phase difference technique. $J$ Comput Assist Tomogr 1984;8:588-93.

20 Redpath TW, Norris DG, Jones RA, Hutchison JMS. A new method of NMR flow imaging. Phys Med Biol 1984;29:891-8.

21 van Dijk P. Direct cardiac NMR imaging of heart wall and blood flow velocity. J Comput Assist Tomogr 1984;8:429-36.

22 Moran PR, Moran RA, Karstaedt N. Verification and evaluation of internal flow and motion: true magnetic resonance imaging by the phase gradient modulation method. Radiology 1985;154:433-41.

23 Nayler GL, Firmin DN, Longmore DB. Cine MR blood flow imaging. J Comput Assist Tomogr 1986;10:715-22.

24 Longmore DB, Firmin DN, Nayler GL, Underwood SR, Klipstein RH. Cine magnetic resonance blood flow imaging in clinical use [Abstract]. Magnetic Resonance Imaging 1986;4:157.

25 Klipstein RH, Firmin DN, Underwood SR, Nayler GL, Rees RSO, Longmore DB. Colour display of quantitative blood flow and cardiac anatomy in a single magnetic resonance cine loop. $\mathrm{Br} J$ Radiol 1987;60:105-11.

26 Ernst RR. Sensitivity enhancement in magnetic resonance. Advances in Magnetic Resonance 1966;2: 1-135.

27 Underwood SR, Firmin DN, Klipstein RH, Rees RSO, Longmore DB. The assessment of coronary artery bypass grafts using oblique magnetic resonance imaging and velocity mapping [Abstract]. In: Proceedings of the Fifth Annual Meeting of the Society of Magnetic Resonance in Medicine. Berkeley: Society of Magnetic Resonance in Medicine, 1986;5:47-8.

28 Singer JR. Blood flow rates by nuclear magnetic resonance measurements. Science 1959;130:1652-3.

29 Feinberg DA, Crooks L, Hoenninger J III, Arakawa $M$, Watts J. Pulsatile blood velocity in human arteries displayed by magnetic resonance imaging. Radiology 1984;153:177-80.

30 Singer JR, Crooks LE. Nuclear magnetic resonance blood flow measurements in the human brain. Science 1983;221:654-6.

31 Wedeen VJ, Rosen BR, Chesler D, Brady TJ. MR velocity imaging by phase display. $J$ Comput Assist Tomogr 1985;9:530-6.

32 Jacobstein $\mathrm{MD}$, Fletcher BD, Goldstein S, Riemenschneider TA. Evaluation of atrioventricular septal defect by magnetic resonance imaging. $A m \mathrm{~J}$ Cardiol 1985;55:1158-61.

33 Dinsmore RE, Wismer GL, Guyer D, et al. Magnetic resonance imaging of the interatrial septum and atrial septal defects. Am J Roentgenol 1985;145:697-703.

34 Lowell DG, Turner DA, Smith SM, et al. The detection of atrial and ventricular septal defects with electrocardiographically synchronised magnetic resonance imaging. Circulation 1986;73:89-94.

35 Feiglin DH, George CR, MacIntyre WJ, et al. Gated cardiac magnetic resonance structural imaging: optimization by electronic axial rotation. Radiology 1985;154:129-32.

36 Feiglin DH, Moodie DS, O'Donnell JK, Go RT, Sterba R, MacIntyre WJ. Evaluation of congenital heart disease by cine magnetic resonance imaging [Abstract]. Eur J Nucl Med 1985;11:A18.

37 Utz JA, Herfkens RJ, Heinsimer J, Glover GH, Pelc NJ, Shimakawa A. Rapid dynamic MR imaging of the heart in the evaluation of valvular function [Abstract]. Radiology 1986;161(P):198.

38 Nakagawa H, Yamamoto K, Takamiya M, Sakakibara $H$, Nimura Y. Semiquantitative grading of severity of mitral regurgitation by real-time two-dimensional Doppler flow imaging technique. J Am Coll Cardiol 1986;7:82-8.

39 Miyatake K, Izumi S, Shimizu A, et al. Right atrial flow topography in healthy subjects studied with real-time two-dimensional Doppler flow imaging technique. J Am Coll Cardiol 1986;7:725-31.

40 McLennan FM, Haites NE, Mackenzie JD, Daniel MK, Rawles JM. Reproducibility of linear cardiac output measurement by Doppler ultrasound alone. Br Heart J 1986;55:25-31.

41 Goldman ME. Real-time two-dimensional Doppler flow imaging: a word of caution. J Am Coll Cardiol 1986;7:89-90.

42 Hatle L, Brubakk A, Tromsdal A, Angelsen B. Noninvasive assessment of pressure drop in mitral stenosis by Doppler ultrasound. $B r$ Heart $J$ 1978;40:131-40.

43 Hatle L, Angelsen BA, Tromsdal A. Non-invasive assessment of aortic stenosis by Doppler ultrasound. Br Heart J 1980;43:284-92.

44 Herfkens RJ, Higgins CB, Hricak $\mathrm{H}$, et al. Nuclear magnetic resonance imaging of atherosclerotic disease. Radiology 1983;148:161-6.

45 Wesbey GE, Higgins CB, Amparo EG, Hale JD, Kaufman L, Pogany AC. Peripheral vascular disease: correlation of MR imaging and angiography. Radiology 1985;156:733-9.

46 Jenkins JPR, Love HG, Foster CJ, Isherwood I, Rowlands DJ. Magnetic resonance imaging in the assessment of coronary artery bypass graft patency [Abstract]. Br J Radiol 1986;50:853-4.

47 Nayler GL, Firmin DN. Multislice MRI angiography [Abstract]. Magnetic Resonance Imaging 1986;4:156. 